\title{
versants
}

\section{Y-cidad: los múltiples sentidos de «y»}

Mieke BAL

Amsterdam School for Cultural Analysis (ASCA)

\begin{abstract}
Las reflexiones sobre el arte político deben tener en cuenta las dos partes del sintagma -no solo político, sino también arte-. Mediante ejemplos de un poderoso arte contemporáneo políticamente comprometido, el artículo concluye que el arte político no es tanto activista como activador. En lugar de buscar la participación en asuntos políticos, tal arte busca afectar a los observadores y así hacerlos sensibles a lo que el arte puede hacer por la vida social.
\end{abstract}

Keywords: Arte, activismo, activador, abstracción, anacronismo, refugiados.

\section{Triple A}

¿Cómo puede el arte ser políticamente relevante sin convertirse en propaganda? Esta cuestión ha centrado mi interés investigador durante la última década. Empezó con un libro sobre la artista colombiana Doris Salcedo, cuya obra me impresionó profundamente cuando la vi por primera vez. Si queremos establecer categorías, su obra debería calificarse como escultórica; pero lo cierto es que se caracterizaría mejor como una intervención artística en el espacio. ¿Y qué es eso del arte? A veces, uno contempla una obra de arte y, al internarse en el espacio de la exposición, uno mira atónito a su alrededor. ¿Dónde está la obra de arte? Así fue mi primer encuentro con la obra de Salcedo, su instalación Unland (1997).

La obra de Salcedo es un intento de conferir forma, reconocimiento y materialidad al dolor. Estas obras son apelaciones temporales a los espectadores, exigiéndoles dedicar un tiempo de consideración a las víctimas cuya visión tendemos a rehuir porque su dolor nos molesta. Ella despliega arte para impeler a los espectadores a convertirse en testigos, a dejar de condonar la violencia y a repensar sus propias posiciones políticas. Lo que querría proponer, entonces, es sustituir el calificativo activista por activador, de tal manera que podamos acercarnos a esa combinación de criticidad y solidaridad que vincula nuestros afectos. Lo que pretende mi visión sobre la $y$-cidad en la frase arte y activismo es que aquellos que estudian el arte se centren menos en el arte activista que en el arte activador.

Las tres tablas que constituyen Unland (1997) son obras en las que, por un lado, la fragilidad de las superficies resulta sobrecogedora hasta el punto de

I Traducción del inglés de un artículo inédito por Natalia Fernández Rodríguez. 
que uno casi no se atreve a acercarse; por otro, las tablas son apenas visibles como arte -para verlas, uno se siente empujado a mirar más de cerca-. La clave es que el hecho de mirar a las esculturas requiere rendición; rendición no a una forma de dolor, sino a su temporalidad. Es entonces cuando, retrospectivamente, te das cuenta de que esa primera mirada ya era una respuesta; algo que la obra te hizo hacer. Y así, el juego llamado arte comienza sin una definición previa de lo que es el arte. Este planteamiento me viene bien, porque estoy más interesada en lo que hace el arte que en lo que es el arte. Ese arte es una apelación, una provocación. Lleva a los espectadores a pensar. Ese es, esencialmente, el aspecto político, o el poder, del arte. Al mismo tiempo, desafía ideas comunes del arte político. Porque, como la obra de Salcedo es no representacional, es silenciosa, su potencial para contribuir a lo político tampoco es obvio (Bal 20Io).

Siempre he tenido muy presente la cuestión del potencial político del arte. Recientemente, casi una década más tarde, se me encargó responder a una ponencia sobre Arte \& Activismo a cargo del historiador del arte y activista afincado en California T.J. Demos. Más que cuestionar el calificativo político de la frase arte político, esta formulación del tema se centra en algo ligeramente distinto. ¿Cómo se relacionan arte y activismo? En otras palabras: ¿Qué significa $y$ ? Esta cuestión, el significado de $y$, ha estado en mi mente durante largo tiempo. No puede ser una simple acumulación de asuntos. En I977, la profesora americana de literatura francesa Shoshana Felman planteó la cuestión acerca de la literatura y el psicoanálisis. Siempre tendré presente su respuesta magistral -o, mejor, rechazo o pluralización de la respuesta- (Felman I977: 5-IO) ${ }^{2}$.

Cuando se trata de un congreso -ese formato académico de discusión donde se presentan a debate las nuevas ideas, con el objetivo de avanzar en nuestra búsqueda colectiva de conocimiento e introspección- hay un tercer miembro en la relación: los estudiantes y colegas que aspiran a entender esa controvertida conjunción $y$, para sustituir acumulación por relación. Lo mismo es aplicable a los lectores de una revista. El público, apasionado por las cuestiones políticas cruciales en nuestro mundo actual tanto como por el arte, la literatura, la filosofía y esos otros campos que llamamos humanidades en un momento en que incluso lo humano como tal está bajo amenaza y bajo crítica, se reúne en congresos; como el congreso celebrado en Berna (Suiza) en Octubre de 20I7, Lo que vemos, lo que nos mira, cuyo título apunta a la mutualidad y performatividad del arte. También es aplicable a los lectores de revistas que leen, precisamente, porque quieren aprender algo. $\mathrm{Mi}$ esperanza es que todos los participantes en los debates académicos estén

2 La importancia de la y-cidad se discute en profundidad en mi libro sobre la abstracción como políticamente relevante ( $\mathrm{Bal}$ 2013). 
deseando aprender los significados de esa conjunción y para dar sentido a la relevancia de su investigación académica. En otras palabras, que les apasionen las relaciones entre esos campos. T.J. Demos es un excelente ejemplo de académico que rechaza las separaciones impuestas sobre los académicos. $\mathrm{Su}$ trabajo es un vehemente ejemplo de cómo un académico puede, sincera y profundamente, comprometerse con el conflicto político de nuestro mundo actual.

En su mencionada introducción al apartado sobre Literatura y Psicoanálisis de la revista Yale French Studies, Felman escribió sobre

the misleadingly innocent, colorless, meaningless, copulative conjunction 'and' that, like the terms it connects, must be reinvented to be put to work, so as to avoid the subordinative tradition where a body of knowledge is a subject to which the object of analysis is subjected, as its object. The conventional notion of «application» is displaced by that of «implication» (1977:5).

Esto conlleva un impacto mutuo que no es jerárquico; un pliegue del uno sobre el otro, una interioridad mutua. Tengamos presente ese repliegue entendido como implicación mutua.

La cuestión de las dos y-es -arte y activismo, y la tercera, una búsqueda académica de introspección en la relación- es suficientemente compleja para llevarnos a un pensamiento más y más profundo. El reto de que esto es difícil, para reciclar el calificativo que utilizó el artista chileno Alfredo Jaar para sus intentos de hacer un arte político no voyeurista, ayudará contra la desidia intelectual, contra la recaída en los hábitos y automatismos que llamamos métodos, y otras enfermedades del actual clima académico. Activismo: la acción política activa ejercida en público para propugnar y activar ideas importantes. El arte es imposible de definir; e intentar hacerlo está condenado al fracaso por ser reduccionista. En todo caso, sabemos que el arte implica la construcción de objetos poderosos, inútiles; un hacer perceptible, un dar forma de un modo que compromete ideas, impresiones, pensamientos efímeros o perniciosamente obstinados; y ofreciendo el resultado, esos objetos híbridos, al público en un espacio, de tal manera que estimule el contacto con esas cosas pero también, en un sentido sensorial, con las personas. Esta última sub-cláusula encierra una alusión a la teoría estética del filósofo de mediados del siglo xviII Alexander Gottlieb Baumgarten. Pero puede también concernir al activismo. Activismo y arte tienen, por tanto, algo en común, y el modo en que pueden vincularse recíprocamente, en una implicación mutua, puede ser objeto de examen. En esencia, es todo una cuestión de tiempo -de tiempo hecho sensible, material y contagioso3.

3 Para el antiguo sentido de estética, véase Baumgarten (1970). Este libro, muy largo, escrito en latín no ha sido traducido al inglés. Puede consultarse mejor Hlobil (2009). 


\section{Conjunciones}

Hasta qué punto puede unirse la reflexión académica con otra, en conjunción, es una cuestión compleja -que intento discutir aquí-. Me propongo plantear que el trabajo académico, especialmente la investigación, pero también la docencia, es compatible tanto con el arte como con el activismo; también empieza con una A. Al titular su reciente publicación Against the Anthropocene, y poner en cuestión los diferentes conceptos y sus implicaciones, diría que T.J. Demos ha de-naturalizado un término que, aunque nuevo, ya ha encontrado su lugar en los automatismos. Y guiándonos a través de un bosque de alternativas, ha especificado el asunto para el que se invoca el activismo -el inminente desastre ecológico, de hecho, destrucción del mundo-. El lado académico de este activismo reside en desvelar las implicaciones del concepto antropoceno, pero este gesto analítico no puede separarse del aspecto activista, teniendo en cuenta que todos sus argumentos tienen implicaciones políticas. Aquí es donde la conjunción entre las tres Aes comienza a tomar forma ${ }^{4}$.

De su pluralización conceptual, secundaría su preferencia por capitaloceno para reunir legibilidad, especificidad histórica e idea central, especificar causas y acercarnos a nuestros roles. Como una performance conceptualizadora, el trabajo de Demos es una obra de arte de esas que encarnan activismo; que es activista. El trabajo representa algo que propondría denominar obra de arte conceptual de activismo. Había acabado de releer el libro de Demos sobre The Migrant Image. Este libro se convirtió para mí en un modelo de la conjunción de la tríada de palabras con $A$ enlazadas con dos y-es: arte \& activismo \& reflexión académica. No conozco ningún otro estudio que ofrezca un equilibrio tan perfecto entre teoría, pensamiento político, lectura atenta de obras de arte, activismo y, donde resulta relevante, filosofía. El libro es rico en todos esos dominios, o campos, y en la integración de todos ellos. Se centra en lo documental, pero esa palabra del subtítulo adquiere, además, un nuevo y revitalizante sentido. Tendemos a pensar que es fundamentalmente sobre la realidad.

Las múltiples obras de arte que revisa, todas con la suficiente profundidad para hacerles justicia, son, sin embargo, obras del artes: obras-del arte,

\footnotetext{
4 No dispongo de espacio para profundizar en sus argumentos contra el concepto. Es suficiente señalar que la primera palabra del título, against, ya afirma el propósito polémico del libro Against the Anthropocene: Visual Culture and Environment Today (Demos 2017). Antes de esto, Demos publicó una obra de temática similar, Decolonizing Nature: Contemporary Art and the Politics of Ecology (2016). El libro de Demos que considero más convincente respecto al $y$ es su The Migrant Image: The Art and Politics of Documentary during Global Crisis (2013). Volveré a este libro más adelante.

5 La autora distingue artwork y work of art para resaltar, con este último término, el potencial activador del arte. Nota de la traductora.
} 
arte que obra: obra por asuntos sociales y políticos, sin ignorar ni por un segundo la estética. Y Demos demostró -en un análisis académico, esto es, accesible a la vez que profundo- cómo las obras de arte como arte, se implican en los candentes asuntos políticos de la actualidad. Mediante argumentos lo más refinados y matizados posible, aunque siempre con una perfecta claridad, no desprecia, pero tampoco adula de forma gratuita. Estas son dos tendencias del pensamiento contemporáneo que, junto a la simplificación (que lleva a los gritos tipo tweet, tipo Trump) y la oposición binaria, consigue evitar a la perfección. Que los tweets que actualmente dominan el mundo no pueden competir con el pensamiento es obvio. Pero ¿por qué está el pensamiento binario tan extendido que se ha naturalizado completamente y se ha convertido en algo tan destructivo? La oposición binaria implica tres desplazamientos, todos perjudiciales para el conocimiento: reduce la complejidad a simplicidad, ayudándonos a entender lo que es difícil, pero también haciendo que olvidemos la complejidad. Reduce, además, las posibilidades a dos polos únicos, en oposición recíproca. Y ordena los dos polos jerárquicamente, de tal modo que uno es valorado positivamente y el otro no. De esta estructura proceden el racismo, el sexismo, los prejuicios contra la edad, las divisiones ricos/pobres y otras formas de marginar a grupos que no disponen del poder para exigir su participación -como los jóvenes-. Ver los vídeos, páginas web, fotografías que Demos analiza con tal sutileza y leer sus comentarios es la mejor educación en las artes y en la política -y, lo más importante, en el vínculo entre ambas a través de la reflexión académica.

Este libro es una auténtica obra maestra de lo que yo llamo análisis cultural. Es activista en su manera concreta de analizar las obras de arte, y, en el movimiento mutuo de $y$, demuestra el desarrollo analítico del arte; el modo en el que el arte revela lo que el discurso ordinario puede solo circunscribir de una forma vaga. Los dos libros que siguen se alejan un poco de esa triple y-cidad, y querría volver a ella. Especialmente el libro más reciente se centra menos en el análisis artístico, que parece haberse quedado al margen. Los rápidos ejemplos de obras de cultura visual no satisfacen mi interés central en el modo en que el arte, con los aspectos que esbozaba arriba, puede hacer trabajo político sin ser sobre política. Un ejemplo de arte político que toca $-\mathrm{y}$ nos conmueve con- la política sin representarla es el arte que obra del gran artista sudafricano-holandés Marlene Dumas. El aparentemente simple título de su excepcional cuadro de 2009, Mindblocks, participa totalmente del activismo y utiliza la reflexión académica para desvelar sus sentidos complejos. En la obra de Dumas, que está siempre políticamente comprometida, este cuadro es excepcional, pero podemos considerarlo también programático, si lo entendemos como el que glosa todas sus otras obras; lo que el historiador del arte francés Hubert Damisch llamaría un objeto teórico. Con este término se refiere a una obra de arte que: 
[...] obliges you to do theory but also furnishes you with the means of doing it. Thus, if you agree to accept it on theoretical terms, it will produce effects around itself [...] [and] forces us to ask ourselves what theory is. It is posed in theoretical terms; it produces theory; and it necessitates a reflection on theory (Bois et al. 1998).

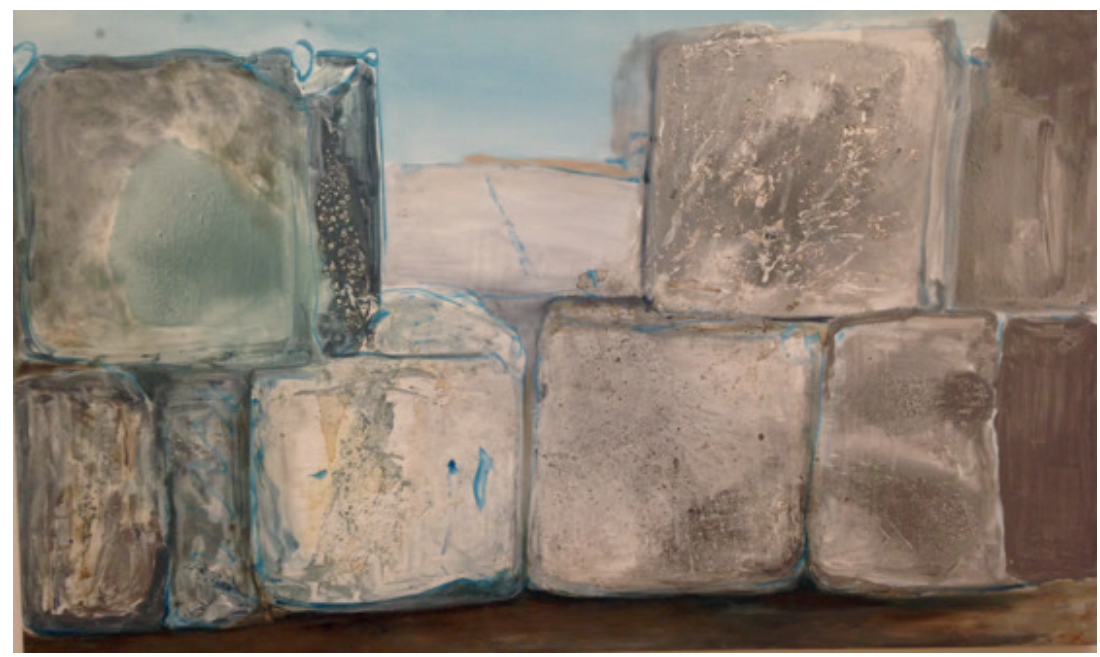

Marlene Dumas, Mindblocks. Pintura, 2009.

Veamos cómo Mindblocks puede ser tal objeto. Es abstracto en el sentido de que no se representa ninguna figura humana, mientras la mayor parte de la obra de Dumas se centra en los humanos; y, sin embargo, es figurado. Es más: es una materialidad cimentada, en el sentido de ese material sólido de construcción $^{6}$; los bloques son representaciones de bloques; y el color sutil y, especialmente, los efectos de superficie plantean una cuestión estética: a la izquierda, el color evoca el color del agua, ese material sutil y ligeramente transparente. A la derecha se alude a lo que parece un arañazo o grabado en la roca.

El título se refiere también a un término ampliamente conocido. Un bloqueo mental cierra la mente al pensamiento y, en este sentido, la obra ofrece una crítica del dominio político cuando la gente tiende a bloquear sus mentes ante las posiciones de otros. Las concepciones tradicionales de la abstracción no parecen encajar en esta pintura. Pero hay otra visión sobre la abstracción desarrollada por el filósofo Gilles Deleuze que, más que negar

6 La autora juega con el término inglés concrete, que también hace referencia al hormigón. Nota de la traductora. 
la forma, ofrece posibilidades de nuevas formas. Dumas toma esa visión en serio y de manera literal: su muro de bloques bloquea lo que podemos ver, pero entre las filas de bloques percibidos como cuadrados, uno de ellos parece una carretera avanzando hacia un futuro donde una mancha de ocre en la esquina superior derecha evoca un paisaje desértico de Oriente Medio o de África -partes del mundo que Occidente ha abandonado y que están empezando a exigir atención-. Podemos verlo a través de los huecos entre los bloqueos mentales.

La alusión a nuestra ceguera política, junto al muro que convierte Gaza en un campo de concentración, y el muro de las lamentaciones en Jerusalén, el camino de arena que conduce a un distante punto de fuga que aquí se toma literalmente, todos trabajan para estimularnos a pensar en cómo funcionan los bloqueos mentales y obstaculizan una acción política muy necesaria. Me interesa ese arte no temáticamente activista porque despliega otros medios de estimular el pensamiento que infectarían incluso a esas personas que no estuviesen ya políticamente en el mismo lado. Mientras tanto, los planos de las rocas son hermosas porciones abstractas. ¿Pero qué puede significar eso? Deleuze rechaza la lógica negativa tanto como la oposición binaria resultante de las nociones estándar de abstracción. Prefiere los y-es de las relaciones a los no-es de conexiones definidas negativamente; nudos, mejor que noes ${ }^{7}$. Para Deleuze y Guattari, la abstracción es la exploración de un mundo desconocido de formas posibles, todavía no inventado. La abstracción, para ellos, no es lo opuesto a la figuración sino que, imaginado sobre un eje de lógica temporal, lo precede. Para Deleuze, los artistas abstractos pospondrían la forma, incluso si ellos (provisionalmente) rechazan la representación. Las obras de arte presuntamente abstractas dan a entender formas por llegar; son signos deícticos de una temporalidad prospectiva, orientada hacia el futuro. En su sofisticada e inevitable interacción entre el color y la representación de situaciones sociales, esto es bastante radical. Al continuar la figuración a través de, y anudada a, la abstracción, Dumas desbanca la negatividad de la abstracción, y, en su lugar, establece conjunciones ${ }^{8}$.

\section{¿Por qué arte?}

¿Por qué arte, en el sentido comúnmente entendido? Mucha gente se siente atraída por el arte porque le ofrece un refugio temporal ante la des-

7 La autora juega con la homofonía knot-not. Nota de la traductora.

8 Esta es una simplificación de la idea de abstracción que proponen Deleuze y Guattari. Rajchman ha sintetizado la visión de los filósofos en un artículo fundamental desarrollado posteriormente como libro (1995 y 1998). 
garradora realidad exterior, en un universo ficcional que estimula su pensamiento racional. $Y$ esas personas deben ser políticamente activadas en su puro compromiso artístico. Durante más de una década, me ha interesado la exploración de estrategias artísticas y el modo en que despliegan medios particulares, utilizando la temporalidad para persuadir a los espectadores y lectores a pensar, primero con la obra de arte, luego, más allá, por sí mismos, alcanzando sus propias conclusiones, en una libertad activa para la que el arte tiene el potencial de crear el clima adecuado. La obra de Salcedo impulsó esa reflexión.

Para aclarar lo que quiero decir, me permito aludir a la obra de otros artistas políticos que he estudiado; artistas que se consideran a sí mismos activistas en el sentido que el arte permite esa caracterización. A través de esa alusión intento demostrar también que el arte, en este concreto sentido performativo-activista, se ha globalizado a sí mismo, de tal manera que la especificidad regional se está convirtiendo de algún modo en obsoleta, incluso aunque la aguda división entre regiones ricas y pobres siga siendo un asunto de gran preocupación. La artista india Nalini Malani emplea la pintura -el medio más tradicional- en un estilo que fusiona diferentes estilos tradicionales a través de los que homenajea el legado de las tradiciones de pintores pobres que tuvieron que utilizar pigmentos naturales para poder costear su trabajo, pero que también, de esa manera, evitaban la contaminación; y apela a la desigualdad de clases, y a la cruel explotación de personas y tierra que la acompaña. Comprender esa multiplicidad semántica y formal es ya una estrategia activadora, desde el momento en que la combinación de formas simples y refinadas, desproporciones de escala e iconografías de crueldades míticas e históricas, especialmente para las mujeres, persuade a los observadores a reflexionar sobre estas cuestiones. Ella experimenta con formas inusuales dentro de las que sus juegos de sombras constituyen los ejemplos más célebres9.

9 Sobre las estrategias de Malani para mostrar la pintura como activista, véase mi artículo «Stains against violence: Nalini Malani’s strategies for durational looking» (Bal 20I7). 


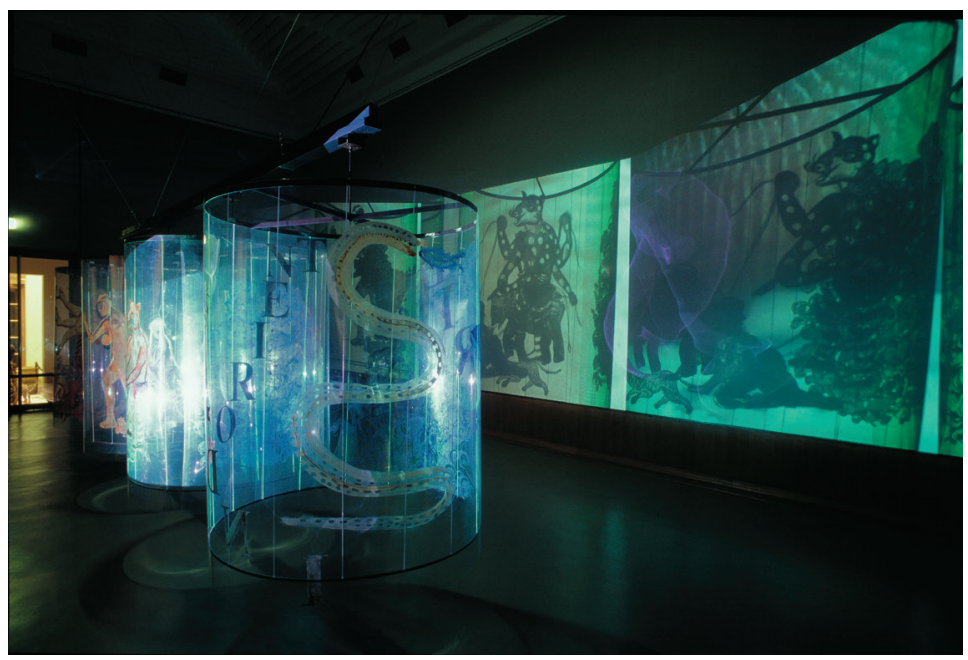

Nalini Malani, Transgressions. Obra de vídeo y sombras $200 \mathrm{I}$.

Superponiendo estas formas, por decirlo así, convierte el tiempo en herramienta central para estimular a los espectadores. Consisten en cilindros transparentes que lentamente giran sobre sí mismos cuatro veces por minuto. Es lo suficientemente lento para mantenernos alerta e interesados, y demasiado rápido para absorber los detalles del estilo y la narración que hacen la obra tan atractiva. Este ritmo concreto es el primer mecanismo de activación. Hace que los espectadores quieran esperar el siguiente giro y así asimilar los mensajes políticos, sobre todo en un sentido anticapitalista, antiglobalizador, anticasta y antipatriarcal. La originalidad del medio o género y la belleza de la obra pictórica hace que los visitantes deseen voluntariamente emplear su tiempo en entenderla, y-¿quién sabe- actuar a partir de las impresiones adquiridas ${ }^{\mathrm{IO}}$.

En una forma artística muy diferente, la artista finlandesa Eija-Liisa Ahtila lleva la temporalidad a una instalación de vídeo. Utiliza ese medio, o forma artística, para producir la inmersión - para apelar al interés de la gente por estar rodeado por pantallas de video o, como aquí, frente a una fila de pantallas que transmiten mediante una escala auténtica la realidad de lo que se está destruyendo-. El medio de la instalación de vídeo empuja a los espectadores a pensar, por usar la expresión de Brian Massumi, mediante un cambio de la secuencialidad temporal por la simultaneidad espacial. Tal montaje lateral combina también una temporalidad imposible -no puedes

Io Para más detalles sobre los juegos de sombras de Nalani, véase mi libro In Medias Res: Inside Nalini Malani’s Shadow Plays (Bal 20I6). 
ver las diferentes pantallas al mismo tiempo- con una lenta, por discontinua, línea narrativa. Ambas cosas dan tiempo para asimilar la complejidad de la nueva composición y uno se siente empujado a mirar de pantalla a pantalla, intentando vehementemente dar sentido a las combinaciones. Como resultado, las conexiones entre momentos históricos y preocupaciones actuales se hacen visibles y tangibles, de tal modo que el pasado colonial puede verse como presente en el presente, cuando tenemos la necesidad de distinguir entre culpa y responsabilidad ${ }^{\text {II }}$.

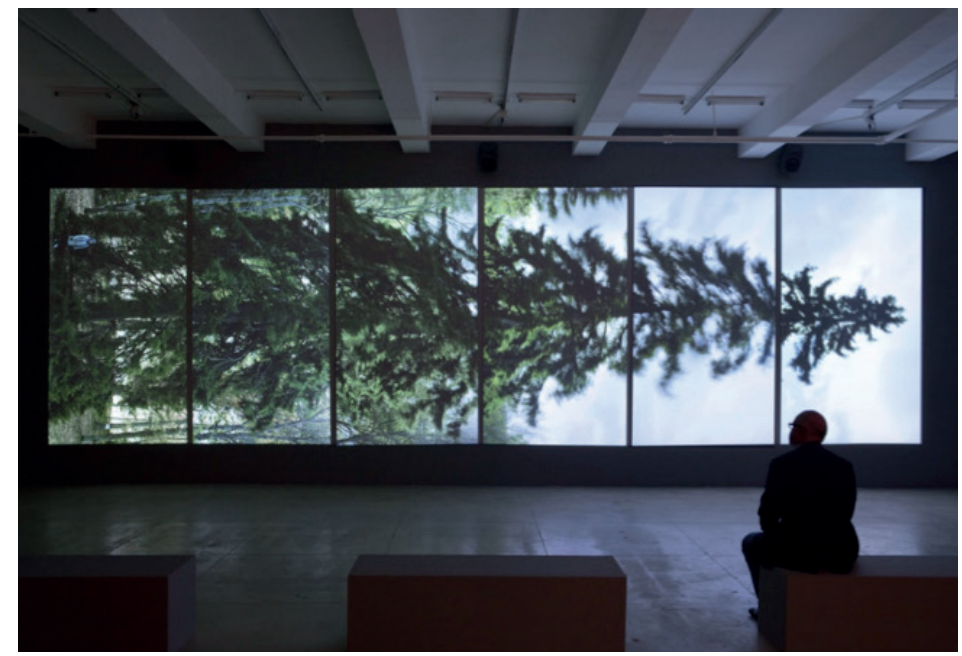

Eija-Liisa Ahtila, Horizontal, 201.

Las instalaciones de Ahtila, especialmente su obra maestra Where is Where? de 2007, nos conducen a reconocer la responsabilidad Espinozista en las consecuencias actuales de una colonización que nos considera - post con demasiada facilidad, sin una culpa que se ignora muy facilmente por no haber nacido cuando sucedió. La responsabilidad, tanto por la violencia que genera la locura como por la explotación colonialista que genera la migración, es un deber social, forzado por una ética a la Spinoza. Este filósofo, un sujeto migratorio del siglo xvII, cuyos padres fueron refugiados, es un ejemplo inaugural, poderoso, de la productividad anacrónica de hacer conjunciones a través de una cuarta palabra A: anacronismo. Spinoza es cada vez más reconocido como un pensador clave para referirse al predicamen-

II Sobre la útil idea de empujar al pensamiento, véase Massumi (2002). Tomo el término montaje lateral de Manovich (200I: 325). 
to histórico consistente en la confusión de culpa y responsabilidad. En este contexto, los escritos de Spinoza sobre el afecto cobran relevancia, igual que la teoría de la imagen afectiva de Deleuze. Como las filósofas australianas Gatens y Lloyd admiten,

[...] the complex interactions of imagination and affect [...] yield this common space of intersubjectivity [...] and the processes of imitation and identification between minds which make the fabric of social life (Gatens y Lloyd 1999: 40) ${ }^{12}$.

Aquí es donde la imagen afectiva, que teorizó Deleuze como situada emblemáticamente en el primer plano, aparece con su típica temporalidad. Los primeros planos subvierten el tiempo lineal. Se mantienen y, por tanto, inscriben el presente en la imagen. Entre las imágenes narrativas y los primeros planos, por tanto, emerge un tipo particular de intermedialidad; una que escenifica una lucha entre narrativa rápida y quietud. La entre-temporalidad que entra en juego aquí toma su punto de partida del presente -el presente de la mirada.

Otro modo y medio en que la temporalidad es la herramienta de activación es la obra más reciente de Salcedo, expuesta por primera vez en 20I7-I8 en el Palacio de Cristal, en Madrid. Un sutilísimo y diminuto movimiento se extiende a lo largo de una inmensa plaza en forma de grandes bloques color arena, de superficie granulosa y diseñados para resistir la absorción de agua. Nombres casi borrados están escritos sobre ellos, en arena. Otros nombres se sobreescriben a estos, en un grabado superficial. De repente, una gotita de agua aparece, deslizándose hacia el relieve; después un poco más, hasta que las letras del nombre se rellenan y el agua se convierte en una brillante superficie convexa, rebasando la planitud de los bloques. Tras unos pocos minutos, las letras de agua comienzan a temblar; después, desaparecen. Aparición y desaparición: los nombres siguen moviéndose -como la inestabilidad física y como un efecto emocional- produciendo agitación. Los nombres de agua se superponen a los nombres de arena, que se mantienen como un palimpsesto, un rastro de personas olvidadas.

Salcedo, cuya obra de arte se ha dedicado desde comienzos de los 80 a mostrar el olvido de la violencia y la violencia del olvido, ha creado, durante cinco años y con un equipo de veinte personas, la instalación de arte político más brillante que he visto nunca. El término contra-monumento (Andreas Huyssen), aunque sin duda apropiado, no es suficiente para definirla. Es también una obra performativa que sigue moviéndose y cambiando. E

I2 Deleuze recibió una profunda influencia de Spinoza. Para una excelente puesta al día de la relevancia del legado de Spinoza en la cultura migratoria contemporánea, véanse Gatens y Lloyd (1999). 
invitando al visitante a caminar sobre ella -no hay otro espacio- incluye al público en la representación. A cada paso uno tiene que decidir si evita pisar los nombres o, lo que parece una indiferencia cruel, caminar sobre ellos. La posibilidad de la indiferencia también conmueve, en el sentido de que los nombres forman un recuerdo y homenaje a las inmumerables víctimas de la indiferencia europea hacia los ahogados en el mar Mediterraneo.

Este no es un tema; la obra no es sobre esta aguda cuestión política. Doris Salcedo no representa la violencia que invoca, ni el olvido que muestra. Aunque su obra nunca es abstracta en el sentido tradicional, nunca proclama opiniones políticas en la alta voz de tanto arte que se autodenomina político. Su obra deconstruye, en línea con Derrida, y después Deleuze, la oposición binaria entre abstracción y figuración. Los objetos de sus obras anteriores son cosas concretas -camisas apiladas, muebles- pero son significativas en un nivel muy distinto, desplegando una luz sutil para llegar a sus espectadores. Sin ni siquiera afirmar un tema, la obra se ocupa de y está comprometida con una causa política. En Palimpsesto, la cuestión en juego es la más trágica y visible de nuestro tiempo gracias a los medios, aunque demasiado conocida para evitar convertirse en invisible. Demasiada arena y muy poca agua empujan a la gente a embarcarse en los precarios barcos de traficantes de seres humanos, solo para morir en tanta agua. Arena y agua: son parte de las condiciones básicas que excluyen la supervivencia, de tal manera que la gente no pueda quedarse donde ha nacido aunque hubieran querido quedarse si hubieran tenido la mínima oportunidad de sobrevivir a la dialéctica negativa de demasiado (arena)-demasiado poco (agua potable)-demasiado (agua de mar). De nuevo, tres términos conectados por dos $y$-es.

\section{Contemporáneo, continuidad, condonación}

Una obra de arte no puede ser más contemporánea -teniendo lugar en nuestro tiempo, hoy-. Y se dedica a esa tragedia de violencia que está sucediendo y que todos nosotros, en Europa, continuamos condonando. Los nombres nos dicen que los ahogados no constituyen una masa anónima, sino un enorme grupo de individuos cuyas vidas importan -cada uno de ellos tan humanos como somos, o fingimos ser, nosotros-. Después de cinco años de trabajo extenuante y creatividad, a costa de una gran inversión de tiempo personal, pensamiento artístico y recursos económicos y, lo que es muy importante, en colaboración con un grupo de veinte personas, $\mathrm{Pa}$ limpsesto muestra la necesidad, aunque dificultad, cultural de hacer duelo, de sufrir por muertos desconocidos; una protesta contra la violencia de la indiferencia y de la aceptación, e incluso una estimulación concreta de la violencia criminal de los gobiernos -no solo el Colombiano, que, por una 198 
débil mayoría, acepta la pérdida del referendum de paz con las FARC-. A este desastre, Salcedo respondió inmediatamente con otra enorme obra de arte, Sumando Ausencias, que cubrió la superficie completa de la Plaza central de Bogotá. Pero ella impele a la población mundial a reconocer la violencia perpetrada por todos los gobiernos y, en este caso, especialmente por los europeos. Una protesta que es, al mismo tiempo, un homenaje a cada una de esas personas, nombradas ahora por su nombre. Ese doble efecto, de pedir indignación y sufrimiento, de belleza y dolor, es inefable. Como Ludwig Wittgenstein afirmó al final del Tractatus, uno debe callarse sobre aquello de lo que no puede hablar. Más tarde, se retractó o modificó esa afirmación cuando dijo que uno debe mostrar aquello sobre lo que no puede hablar. Esta es la razón por la que basé el título de mi libro de 2010 sobre el arte de Salcedo en la máxima de Wittgenstein.

La superficie de esta obra, adaptada a la forma irregular de las muchas columnas, cubre la totalidad del edificio acristalado Art Nouveau del Palacio de Cristal, de I065 metros cuadrados. Cada uno de los 220 bloques mide 4.53 x I.29 metros y pesa 980 kilos. Uno puede imaginar la logística del transporte. La aparición y desaparición del agua ejerce un fuerte impacto. Hace al visitante querer quedarse para ver el agua reaparecer, y así ser observador del acto de observar que esta obra constituye y representa -convirtiéndose en un co-observador-. Uno no puede escribir sobre el agua y la arena no permanecerá en el mismo lugar, pero el artista demuestra que uno puede escribir con agua y con arena. Los nombres escritos en arena pertenecen a víctimas de la indiferencia europea fallecidas antes del año 2000; los nombres escritos con agua a aquellos que murieron después de 2000. Sólo una porción de los fallecidos pudo encontrar un lugar en esta enorme obra. Pero que cada uno cuenta está claro. Tan claro como las gotas brillantes de agua. El nombre es lo que distingue a un ser humano de otro; es la etiqueta de su unicidad. Contra la abyección de la muerte anónima, el brillo del agua dignifica a las personas nombradas. La transparencia y la evaporación del agua con las que los nombres se escriben constituyen una sutil metáfora de la fragilidad de la existencia humana, y en estos casos, de vidas sesgadas demasiado pronto.

Un complejo mecanismo bajo los bloques empuja el agua hacia arriba, gota a gota, hacia la superficie. Cada gota camina hacia las letras esculpidas, a través del diminuto agujero en la roca, entre los minúsculos guijarros. Cuando las gotas emergen, y se despiden de su aspecto brillante donde el sol las hace parecer piedras preciosas, nos damos cuenta de que debemos evitar esa comparación porque nada permanece estable y el material es modesto. En lugar de joyas, vemos lágrimas; la tierra está llorando. Este llanto de la roca está por las lágrimas ausentes de todos nosotros, que nos libramos del espectáculo de las muertes mostrado, en medio minuto, en televisión. En 
su lugar, en la instalación de Salcedo, uno queda lo suficientemente cautivado para pasar un largo tiempo con los muertos. Mientras esperamos que vuelva el agua desaparecida, podemos y debemos tomarnos el tiempo para reflexionar sobre el asunto político mostrado de una manera tan poderosa, precisamente por la ausencia de representación. Por eso, como en todo el arte de Salcedo, el sufrimiento se une con un mínimo esfuerzo para sugerir que podemos, de hecho debemos, romper el ciclo de la violencia silenciada. La herramienta: memoria y (su) tiempo.

La memoria se entiende usualmente como un fenómeno cultural tanto como individual y social. Aunque el término memoria cultural ha sido bastante popular durante las últimas décadas, mi convicción es que esos tres tipos de memoria no se pueden separar. La distinción es solo una cuestión de énfasis, de perspectiva e interés en la parte del sujeto que memoriza. Todas las memorias tienen un aspecto individual, social y cultural. Esto es sencillamente lógico, teniendo en cuenta que los sujetos que recuerdan son también participantes en todos esos dominios. Además, los recuerdos tienen una temporalidad triple. La memoria es una conexión de los tres tiempos de la conciencia temporal humana: el pasado, en el que sucedieron hechos en los que la memoria se compromete -o no-; el presente, en el que el acto de memoria tiene lugar y hacia el que se rescata el asunto recordado; y el futuro, que será influido por lo que los sujetos en el presente, juntos y embebidos en su entorno cultural, recuerdan y hacen con esos recuerdos. En el caso del arte, dominio público, me centro en la memoria cultural; un enfoque que anticipa aspectos políticos y la pluralidad de los sujetos implicados. En la instalación, ningún visitante está solo. El hecho de estar reunidos en un espacio (social) es un aspecto importante de la experiencia; mientras se desarrollan los pensamientos que pide la obra, uno es consciente de estar con esos otros tanto como con los muertos ${ }^{13}$.

La obra de Salcedo aborda la memoria cultural en su negatividad, su fracaso, e intenta encontrar pistas para las soluciones. El fracaso de la memoria no es tanto olvidar, un concepto muy útil del que no debemos olvidarnos al considerar la memoria; y que Aleida Assmann, en su libro Formen des Vergessen, sintetiza como "un filtro, como un arma y como un prerrequisito para la creación de cosas nuevas». En su lugar, el enfoque de Salcedo se orienta, por un lado, hacia una represión activa, aunque no necesaria y deliberada o, desde otro punto de vista, una disociación -en otras palabras, un no-recordar, tal como lo denomina el título de un libro de 2015-; o, por otro lado, obstinadamente hacia lo que puede incluso llegar a la mala fe, la distorsión de memorias potencialmente útiles, como un mal-recordar. Ambas son oportunidades perdidas, devastadoras, ineficientes para el presente

I3 Sobre la memoria cultural, véanse Bal, Crewe y Spitzer (I999). 
y el futuro. Sin moralizar, Salcedo muestra estos fracasos. Puedo pensar en varias razones para rehuir la representación ${ }^{14}$.

Estos dos fracasos de la memoria se confirman en la imaginación cultural en la que y con la que existen los seres humanos. La figura humana constituye la materia prima de la literatura y el arte figurativos, aunque en ningún caso de modo exclusivo. En literatura, especialmente en la narrativa, la figura humana impulsa el desarrollo de la narración. Como agente o paciente, es portador de la acción, que es el motor de la trama. Aquí, esta figura se denomina carácter. Tanto la figura como el carácter pueden considerarse figuraciones: figurativas en que encarnan ideas modeladas en formas, y figuras de apariencia antropomórfica que son, hacen y aparecen. Es la convergencia de figura y carácter en su aspecto de figuraciones lo que proyecta los términos en los que solemos analizar el arte. Veo en la convergencia entre el arte y su análisis el trabajo de la imaginación antropomórfica. $\mathrm{Al}$ acuñar este término, en cierto modo burdo, me refiero a la tendencia a abordar los artefactos culturales desde las lentes o el marco de conceptos antropomórficos frecuentemente desconocidos. Las herramientas de análisis se hacen así congruentes con los objetos.

Esta mirada telescópica de objeto y análisis produce múltiples tendencias cuyas problemáticas señalaré a continuación. Una de esas tendencias es la confluencia de obra de arte e intención del autor. Otra es la unificación de la obra de arte, para parecerse a un ser humano unificado ansioso por mantenerse unido. Una tercera tendencia es la espiritualización, la de-materialización o des-encarnación de arte, hacer arte y ver o leer. Estas tres tendencias producen ejemplos de fracaso de la memoria. Es al mostrar esta tendencia que la obra de Salcedo se entrega a las víctimas necesitadas de recuerdo. Aunque reconocibles por su sutileza y esa intrincada combinación de belleza formal y vacío afectivo, sus obras son imposibles de firmar. También pluralizan a los seres humanos que devuelven a la memoria, descartando por tanto la ansiosa unificación. Y son profundamente materiales. El material, calificado arriba como modesto, de arena y agua, convierte en futil cualquier tendencia espiritualizadora a desencarnarlos. Y aunque la obra es lo suficientemente grande para cubrir un espacio completo de un museo, cada nombre, cada letra, cada gota y cada piedra cuenta como un recuerdo de cada ser humano destruido por la violencia. Es para darse cuenta, sentir y, por tanto, recordar para lo que sirve la obra de arte, que así se convierte en una expresión más seria, efectiva y fuerte que cualquier noticia o debate politico.

En esta obra con y para la memoria, Salcedo se une a otros artistas contemporáneos que despliegan la sombra del pasado como el espectro de los

I4 Sobre la inutilidad del olvido, véase Assmann (2015). 
muertos retornando en el presente. Ese mostrar la continuidad hace su arte contemporáneo. Estoy pensando especialmente en la artista india Nalini Malani y sus famosos juegos de sombras, evocadas brevemente arriba. La sombra como rastro, así como los nombres escritos en arena en Palimpsesto, se convierte en un espectro cuando tenemos en cuenta el tiempo en sí mismo. Y el tiempo es el motor de la memoria, así como del olvido, del no-recuerdo y del mal-recuerdo. Cuando pensamos en el tiempo, no podemos ignorar la historia, pero estoy bajo el impacto de la contemporaneidad de esta obra de arte, por tanto, de la historia del presente. Ahí, la pluralidad de experiencias del tiempo llevan a lo que he denominado heterocronía ${ }^{15}$.

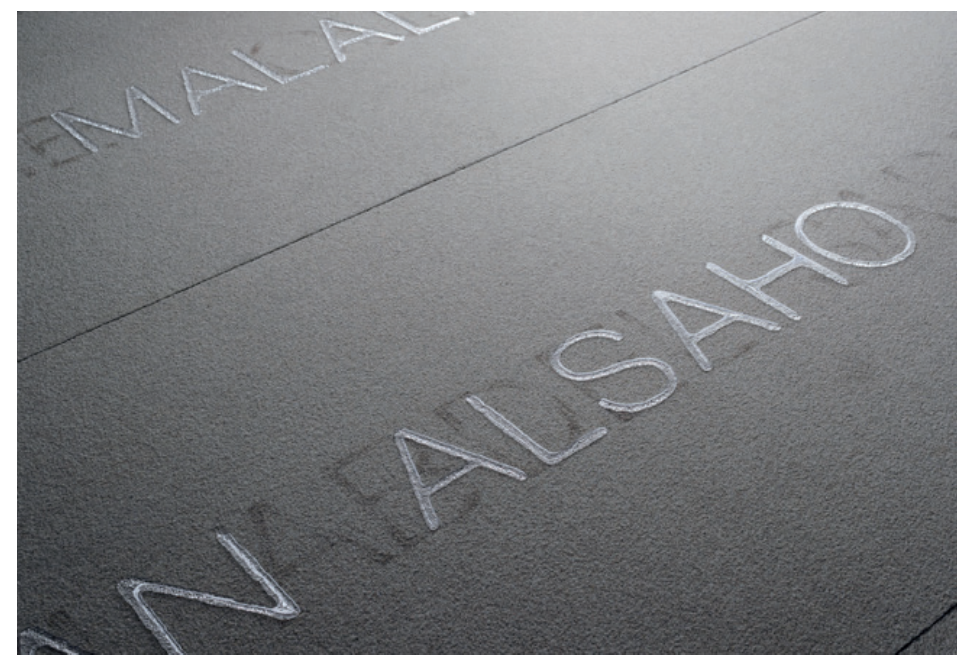

Doris Salcedo, Palimpsesto, 2017.

Una de las diferencias de duración en las varias experiencias del tiempo es la duración de la mirada. La imagen cristalina deleuziana, esa unidad enredada de una imagen real y su imagen virtual donde vemos el brote de momentos de tiempo a través de varias facetas del cristal como si se doblaran: todas estas formas temporales se activan en el cristal contemporáneo de esta obra de arte multi-tentacular. Salcedo, cuyo arte se ha dedicado consistentemente a mostrar el olvido de la violencia y la violencia del olvido ha hecho una obra ejemplarmente performativa, que sigue moviéndose y cambiando. En Palimpsesto, Salcedo de-naturaliza nuestra condonación de

I5 Sobre la heterocronía, véanse Bal y Hernández-Navarro (2008). 
lo que sucede, mientras lo acerca tanto que la indiferencia apenas puede sostenerse $^{\mathrm{I} 6}$.

\section{Arte y / como filosofía; en alabanza del anacronismo}

Estas artistas y muchos otros -mencioné brevemente a Alfredo Jaarestán en diálogo con, o responden a, algunos de los grandes pensadores. Foucault escribió sobre las condiciones de visibilidad que se mantienen invisibles, y estos artistas, entre muchos otros, despliegan el arte para hacer que se tome conciencia de esas condiciones; para activar a los espectadores. Como he mencionado, Ludwig Wittgenstein afirmó al final del Tractatus, de lo que uno no puede hablar, uno debe callarse. Y en las palabras de las dos filósofas australianas contemporáneas citadas arriba, Spinoza ya clamaba por un arte basado en los afectos y anclado en el presente, donde todos somos responsables, aunque no todos culpables.

El traer a colación a Spinoza pide una breve nota final sobre ese cuarto miembro en el juego de $y$, también comenzando con $A$, que mencioné arriba. La tal vez inesperada participación del anacronismo como un concepto con el que construir la $y$-cidad histórica puede proporcionar a los artistas y académicos un puente que es la version temporal de la globalización. Un ejemplo será suficiente. Antes de Spinoza, Miguel de Cervantes Saavedra (I547-I6I6) escribió uno de los primeros best-sellers tras vivir cinco años de cautiverio como esclavo en Argel (I575-I580). La novela, un anacronismo en sí misma, se lee como una parodia de la épica y los romances medievales que la precedieron y como una precursora de novelas posteriores que se burlan de las historias de aventuras. Pero también resuena en novelas postmodernas del siglo xx y actuales. Lo más importante y, para mí, la motivación que hace avanzar el proyecto en que estoy inmersa, es que El ingenioso hidalgo Don Quijote de la Mancha destaca por su intensidad y expresión creativa de la desesperanza prolongada. Si tal obra literaria ha conseguido y mantenido su status mundial como obra maestra es, ante todo, porque no ha perdido ni un ápice de actualidad. Cada época conoce esas situaciones que empujan a los seres humanos fuera de la humanidad. Actualmente estoy comenzando a diseñar un proyecto de video que habla de esa obra de arte literaria y su actualidad $^{17}$.

Antes, en la historia lejana, sucedieron cosas que todavía suceden, o suceden de nuevo; antes es hoy podría ser el título de una historia anacronista o absurda. La novela no solo es portadora de los rastros del absurdo y la lo-

I6 Teniendo en cuenta que el movimiento es la clave de Palimpsesto, hice un pequeño video documental sobre esto. Véase https://vimeo.com/23984067I.

I7 El proyecto se inició por el actor francés Mathieu Montanier, que hará de Don Quijote. 
cura que sugieren el estado inevitablemente traumático en el que su creador debía estar inmerso tras su regreso a España, rastros modelados en las historias contadas. Pero también sitúa en primer plano esta consecuencia de la guerra y cautividad en la locura de su forma literaria. La literatura reclama su propia identidad medial porque la corriente interminable de aventuras convierte a todas las adaptaciones cinematográficas en esfuerzos más o menos inútiles. Uno apenas puede leer, y mucho menos ver, todos esos intentos sin sentido por ayudar a los otros, cuya consecuencia implica crueldad y dolor. Si, no obstante, intentamos hacer una obra audiovisual basada en la novela es porque la consecuencia de violencia, de estancamiento desesperado en situaciones cuyo final no está a la vista, necesita y merece exploración, de tal modo que los espectadores puedan aprender de ello para manejar sus propias experiencias así como esas otras que otros atisban a su alrededor ${ }^{18}$.

El reto de hacer un proyecto de video basado en Don Quijote apela a dos deseos. Primero, la actual situación del mundo convierte una más profunda reflexion creativa sobre el trauma y su asalto a la subjetividad humana en una tarea urgente para el arte activador. La introspección que la novela alberga se conecta de forma única con otras experiencias de guerra, violencia y cautividad. Segundo, como un medio mayormente narrativo, la película parece la menos apta para hacer justicia a la incoherencia turbulenta, reiteración y aventuras incongruentes contadas en la novela; aunque debido a su capacidad de audio-visualización, un proyecto de video bien pensado puede explorar y transgredir los límites de lo que puede ser visto, mostrado, narrado y observado. En orden a hacer justicia a la peculiar, cíclica, tal vez incluso histérica, forma de la novela mientras se persiguen esos dos objetivos, solo una obra de arte igualmente incoherente y episódica puede resultar efectiva. Pero esta obra de arte debe exceder un plano de forma similar. En vista de la necesidad de observar, tal forma faculta a los observadores para construir su propia historia y conectarla con lo que han visto a su alrededor. Por tanto, intentamos transformar la histeria de una narración interminable en una reflexion sobre la comunicación más allá de los límites que la locura dibuja alrededor de sus cautivos, y, en su lugar, incluir su subjetividad; brevemente, acercar a Cervantes a nosotros hoy. Cualquier intento narrativo será tartamudeante.

Lo que el psicoanalista francés y teórico de la locura Françoise Davoine llama, citando a Fernand Braudel, poussières d'événements -polvo de acontecimientos- (2006: 43-4) es el motto de esta forma de arte: unas pocas situaciones, momentos sobre el escenario o a través del espacio de la galería. Por

I8 Para una brillante biografía de Cervantes en el ámbito académico colombiano-americano, véase Garcés (2002). Esta biografía se centra en el trauma. También nos inspiramos en dos estudios que proponen lecturas psicoanalíticas: Davoine (2008) y Davoine y Gaudillière (2013). 
eso, la tenue línea de una única narrativa se abandona a una instalación que pondrá al visitante en la posición de crear su propia narrativa a partir de lo que hay allí, mientras observa los acontecimientos. Esto es adecuado al estado de trauma presente en las piezas y a la necesidad de estrechar una mano, en lugar de dar la espalda a la gente herida tan profundamente. El trauma sufrido por Cervantes después de estar a punto de ahogarse, después de ser capturado como esclavo sin ninguna sensación de final de esa situación de desvalimiento y de su sufrimiento, se erige imponente sobre todo el proyecto y determina su forma.

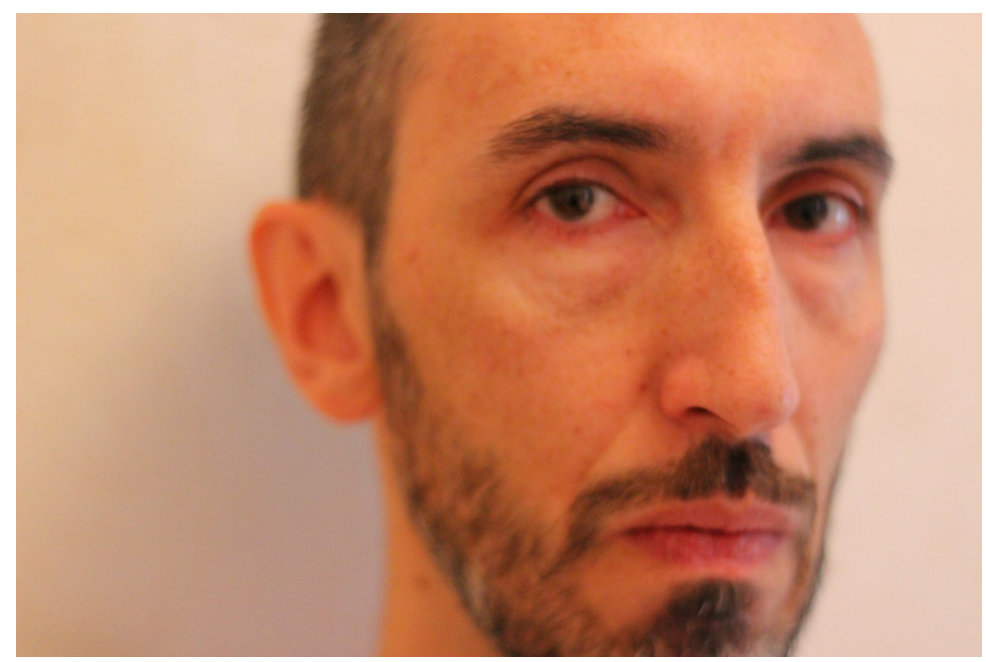

Mathieu Montanier como Don Quijote, 20I8. Fotografía de Sonia Thurel.

La forma de estas piezas será experimental de modos muy diferentes, de tal manera que una estética contemporánea puede alcanzar y tocar una situación de hace mucho tiempo. Predominarán los planos largos, duraderos, preferentemente de 5-8 minutos por plano, después se aumentará la velocidad hasta que vaya demasiado rápido para seguirlo. Otra forma experimental tiene que ver con la relación dinámica entre visibilidad e invisibilidad, imagen y escritura. Un despliegue frecuente de voz en off sin sincronicidad con las imágenes - una novedad en mis obras de vídeo- pondrá en primer plano esta tension. El actor Mathieu Montainer será visible, pero también lo serán las letras de las inscripciones en asociación con otros textos, para poner en primer plano la naturaleza de la vídeo-grafía como una forma de escritura. De ahí, a través de la experimentación con posibles formas del arte del video, buscamos inventar nuevas formas para la no-forma del trau- 
ma. Así, tratamos de honrar a las innumerables víctimas de la violencia, entonces y ahora, a través de un despliegue de la abstracción deleuziana. Otra palabra $y$ que comienza con una A. Pero de todas estas palabras A, activador es la que querría privilegiar, en orden a mantener firmemente en su lugar las conjunciones bosquejadas aquí.

\section{Bibliografía}

Assmann, Aleida, Formen des Vergessen, Göttingen, Wallstein, 2015.

Bal, Mieke, Jonathan Crewe \& Leo Spitzer, eds., Acts of Memory. Cultural Recall in the Present, Hanover, NH, University Press of New England, 1999.

Bal, Mieke \& Miguel Á. Hernández-Navarro, 2MOVE: Video, Art, Migration, Murcia, Cendeac, 2008.

Bal, Mieke, Of What One Cannot Speak: Doris Salcedo's Political Art, Chicago, IL, University of Chicago Press, 20I0, traducción de Marcelo Cohen \& Miguel Á. Hernández Navarro as De lo que no se puede hablar: el arte política de Doris Salcedo, Bogotá, Colombia, Universidad Nacional de Colombia, sede Medellín / Panamericana, 20I4.

-. Endless Andness: The Politics of Abstraction According to Ann Veronica Janssens, Londres, Bloomsbury, 2013.

-. In Medias Res: Inside Nalini Malani's Shadow Plays, Ostfildern, Hatje Cantz, 2016.

-. «Stains against violence: Nalini Malani’s strategies for durational looking», Journal for Contemporary Painting, 4.I, 20I7, pp. 59-80.

Baumgarten, Alexander Gotlieb, Aesthetica [Frankfurt am Main, I750 (vol. I), I758 (vol. 2)], reprint, Hildesheim, Olms, I970.

Bois, Yve-Alain et al., "A Conversation with Hubert Damisch», October 85.8 (Summer), 1998, pp. 3-I7.

Davoine, Françoise, Don Quichotte, pour combattre la mélancolie, París, Stock, L'autre pensée, 2008.

Davoine, Françoise \& Jean-Max Gaudillière, À bon entendeur, salut! Face à la perversion, le retour de Don Quichotte, París, Stock, L'autre pensée, 2013.

Demos, T.J., The Migrant Image: The Art and Politics of Documentary during Global Crisis, NC, Duke University Press, 2013.

-. Decolonizing Nature: Contemporary Art and the Politics of Ecology, Berlin, Sternberg Press, 2016.

-. Against the Anthropocene: Visual Culture and Environment Today, Berlin, Sternberg Press, 20I7.

Felman, Shoshana, «To Open the Question», Yale French Studies: Literature and Psychoanalysis. The Question of Reading: Otherwise, 55/56, I977, pp. 5-IO Garcés, María Antonia, Cervantes in Algiers: A Captive's Tale, Nashville, Tennesse, Vanderbilt University Press, 2002. 
Gatens, Moira \& Genevieve Lloyd, Collective Imaginings: Spinoza, Past and Present, Londres / Nueva York, Routledge, 1999.

Hlobil, Tomáš, «Review of Baumgarten 2007», Estetika: The Central European Journal of Aesthetics, XLVI/I, 2009, pp. I05-IIO.

Manovich, Lev, The Language of New Media, Cambridge, MA, MIT Press, 2001.

Massumi, Brian, ed., A Shock to Thought: Expression After Deleuze and Guattari, Londres / Nueva York, Routledge, 2002.

Rajchman, John, «Another View of Abstraction», Journal of Philosophy and the Visual Arts, 5.I6, 1995, pp. 16-25.

Rajchman, John, Constructions, Cambridge, MA, MIT Press, 1998. 

